\title{
Experimental Study of a Novel Caisson Based Thermal Energy Storage System for Ground Source Heat Pumps
}

\author{
Saunak Shukla ${ }^{1}$, Sylvie Antoun ${ }^{1}$, Aggrey Mwesigye ${ }^{1}$, Wey H. Leong ${ }^{1}$, Seth B. Dworkin ${ }^{1}$ \\ ${ }^{1}$ Mechanical and Industrial Engineering, Ryerson University, Toronto, Canada
}

\begin{abstract}
To avoid the catastrophic results of climate change, a major shift towards clean, sustainable and renewable energy technologies is inevitable. Since buildings are capable of on-site thermal energy generation and exhibiting predictive patterns of heating and cooling, many attempts are currently underway to incorporate more renewable energy (e.g., geothermal heating and cooling) systems in buildings. Subsurface geothermal resources represent a great potential for direct use of energy; put another way, the planet is a six sextillion $\left(10^{21}\right)$ metric ton battery that is continually being replenished by solar radiation, lightning, and heat from its deep-down molten core. Despite the enormous energy potential, geothermal systems are not adopted widely due to three main reasons: high drilling costs, energy imbalance in the ground, and lack of drilling space. To address these challenges, a novel foundation-based geothermal heat exchanger system incorporating phase change material (PCM) has been designed. The proposed technology, utilizing caisson foundation, reduces the construction and installation costs by integrating energy and structural systems together into a single ground installation.

The present study aims to characterize the thermal performance of the proposed system through experiments. The testing facility, which is equipped with a Data Acquisition System (DAQ) connected to multiple temperature sensors, flow rate sensors and a power meter for the compressor, is located in Caledon, Ontario. Since this is the first such system of its kind, several performance parameters need to be characterized. Cycling frequency of the heat pump with respect to average daily outdoor temperature is studied first to confirm the accurate sizing of the components. Then, the influence of variables such as entering source temperature, entering load temperature, and outdoor temperature on the coefficient of performance (COP) is studied. Efficacy of the PCM on improving the thermal performance of the system is also characterized. The overall goal of this study is to consolidate a deep understanding of this novel foundation-based system and ultimately be able to determine the feasibility of its application in commercial and residential buildings.
\end{abstract}

